\title{
EMPREENDEDORISMO E POLÍTICAS PÚBLICAS: PERCEPÇÕES DAS BENEFICIÁRIAS SOBRE O PROGRAMA TRABALHO E EMPREENDEDORISMO DA MULHER EM PERNAMBUCO
}

ENTREPRENEURSHIP AND PUBLIC POLICIES: PERCEPTIONS OF THE BENEFICIARIES ON THE PROGRAMA TRABALHO E EMPREENDEDORISMO DA MULHER IN PERNAMBUCO

\section{Géssika Cecília Carvalho'}

RECEBIDO: 31/01/2017 | ACEITO: 22/05/2017

DOI: $10.5902 / 2317175823997$

\section{RESUMO}

Este artigo deriva de uma pesquisa realizada para tese de doutorado, resultado de um estudo sobre o Programa Trabalho e Empreendedorismo da Mulher em Pernambuco (PTEM) e seus benefícios para as mulheres que participaram de suas atividades. O Programa tinha como objetivo alterar a inter-relação presente nos processos de desenvolvimento local e as questões de gênero, atendendo mulheres em situação de vulnerabilidade por renda (participantes ou não dos programas de inclusão social), apresentando oportunidades de geração de renda, de inserção no mercado e de organização em associações e cooperativas. Foram realizadas entrevistas com dezessete beneficiárias do Programa e os resultados da pesquisa apontaram que o PTEM-PE teve méritos e trouxe benefícios para as participantes, ainda que estes não tenham sido postos como objetivos nos documentos oficiais, pois se referiram mais aos aspectos subjetivos, comportamentais e existenciais. O significado por elas atribuído aos benefícios foi mais perceptível no que se refere às mudanças produzidas nos olhares e opiniões sobre si mesmas e não necessariamente ao seu protagonismo e efetiva participação no desenvolvimento econômico local, inclusive pelo destaque dado por estas mulheres às dificuldades persistentes para criarem ou gerirem um negócio (seja individualmente ou em grupo) e aos obstáculos em garantir a independência financeira em relação aos maridos.

Palavras-chave: Políticas públicas; Gênero; Empreendedorismo.

1Doutora em Sociologia pela UFPB. Mestre em Sociologia pela UFPE. Graduada em Ciências Sociais pela UFPE. Professora do Departamento de Ciências Sociais da UEPB. 
EMPREENDEDORISMO E POLÍTICAS PÚBLICAS: PERCEPÇÕES DAS BENEFICIÁRIAS SOBRE O PROGRAMA TRABALHO E EMPREENDEDORISMO DA MULHER EM PERNAMBUCO

\begin{abstract}
This article is part of research conducted for doctoral thesis, the result of a study of the Programa Trabalho e Empreendedorismo da Mulher in Pernambuco (PTEM) and their benefits for women who participated in its activities. The Program aimed to change the interrelation in local development processes and gender issues, taking account of vulnerable women by income (whether or not participants of social inclusion programs), presenting opportunities for income generation alternatives, market integration and in associations and cooperatives. Interviews were conducted with seventeen beneficiaries of the Program and the survey results showed that the PTEM-PE had its merits and has brought benefits to the participants, even if they have not been the posts as goals in official documents, as mentioned more subjective, behavioural aspects and existential. The meaning for they assigned the benefits was more noticeable with regard to changes produced in looks and opinions about themselves and not necessarily to their role and effective participation in local economic development, including by the emphasis given by these women persistent difficulties to create or manage a business (either individually or in a group) and the obstacles to ensuring the financial independence in relation to husbands.
\end{abstract}

Keywords: Public Policies; Gender; Entrepreneurship.

\title{
1 Introdução
}

Tomando como pano de fundo o contexto de transformações no mercado de trabalho, com o crescimento do número de desempregados, a entrada das mulheres, a precarização do trabalho e a necessidade de busca de estratégias de sobrevivência, as políticas públicas se constituem em ações que - Estado adota para assegurar mudanças na qualidade de vida e nas atitudes comportamentais dos indivíduos. Deste modo, a análise e a avaliação de políticas públicas, independentemente de sua natureza, possibilitam tanto a produção de conhecimentos como a aplicação prática de seus resultados para o aperfeiçoamento do sistema de políticas públicas.

Nessa perspectiva, se insere o Programa Nacional Trabalho e Empreendedorismo da Mulher (PNTEM) que busca, em linhas gerais, fomentar o empreendedorismo e potencializar as oportunidades de emprego, trabalho e ocupação para as mulheres. Tal iniciativa teve origem na Secretaria Especial de Políticas para as Mulheres (SPM), da Presidência da República, em 2007, sendo o Rio de Janeiro o primeiro Estado contemplado com as atividades do Programa, através do desenvolvimento de ações capazes de mobilizar, sensibilizar, capacitar e apoiar processos de inserção econômica e social das mulheres no Estado. Considerando o bom andamento da experiência vivenciada no Rio de Janeiro, expandiu-se para Santa Catarina, Distrito Federal, Pernambuco e Pará.

Assim, este trabalho provém de uma pesquisa realizada para tese de doutorado, resultado de um estudo sobre o Programa Trabalho e Empreendedorismo da Mulher em Pernambuco (PTEM) e seus benefícios para as mulheres que 
participaram de suas atividades. Para esta pesquisa de cunho qualitativo foram utilizados como instrumentos metodológicos a pesquisa bibliográfica e a documental, entrevistas com dezessete beneficiárias da política, e ainda uma análise do conteúdo explicitado no material didático utilizado nos cursos e oficinas.

\section{Empreendedorismo e políticas públicas}

As políticas públicas estão relacionadas à totalidade de decisões e ações do Estado; "são decisões governamentais que geram impacto tangível e mensurável ou substantivo, alterando as condições de vida de um grupo ou população ou produzindo mudanças em atitudes, comportamentos e opiniões". (SILVA E SILVA, 2001, p. 47). Essas políticas constituem um processo decisório em fluxo contínuo, de alteração permanente, que tem como aspectos essenciais as pressões e barganhas. Por esse viés, "[...] toda política pública é uma forma de regulação ou intervenção na sociedade. Trata-se de um processo que articula diferentes sujeitos, que apresentam interesses e expectativas diversas". (SILVA E SILVA, 2008, p. 90). Tais ações do Estado - que são na maioria das vezes resultantes de pressões sociais - representam jogos de interesses relacionados aos aspectos econômicos, políticos, culturais e sociais sendo, portanto, uma forma de mudança social e de redistribuição de renda. Nessa perspectiva, a política pública tem um caráter dinâmico, considerando a interação e a integração dos sujeitos para que ela seja efetiva.

Silva e Bassi (2012) apresentam diversos autores e concepções sobre políticas públicas. Para Heidemann (2009), por exemplo, elas são as decisões (e ações) do governo junto com outras forças da sociedade, incluindo ação e intenção. Já Dye (1984) refere-se "ao que o governo escolhe fazer ou não fazer", traz a perspectiva de decisões governamentais conscientes e deliberadas. E ainda para Laswell (1958) decidir sobre a política pública concerne a questionar quem ganha o quê, porquê e qual diferença faz.

No quadro deste trabalho, uma distinção importante a ser feita é a sobre políticas públicas e programas, uma vez que o objeto deste estudo - o Programa Nacional Trabalho e Empreendedorismo da Mulher - é caracterizado como uma política pública, mas usualmente recebe o nome de Programa Nacional. Segundo Silva e Silva (2008), "as políticas são transformadas em programas quando as condições iniciais são criadas, mas sua materialização só ocorre com a sua implementação, constituindo-se na fase mais abrangente e talvez mais complexa do processo das políticas públicas" (SILVA E SILVA, 2008, p. 96). Isso também é reforçado por Silva e Costa (2002), para quem as políticas públicas se transformam em programas quando, por meio de uma autoridade, as condições iniciais para sua implementação se concretizam.

No campo das políticas públicas de gênero, as principais diretrizes abrangem uma frente ampla sobre violência, saúde, questões relacionadas às meninas e adolescentes, sobre geração de emprego e renda, educação, trabalho, infraes- 
EMPREENDEDORISMO E POLÍTICAS PÚBLICAS: PERCEPÇÕES DAS BENEFICIÁRIAS SOBRE O PROGRAMA TRABALHO E EMPREENDEDORISMO DA MULHER EM PERNAMBUCO

trutura urbana e habitação, questão agrária, acesso ao poder político e empoderamento, transversalidade (incorporação da perspectiva de gênero em toda política pública). Já as políticas de trabalho com recorte de gênero voltam-se para a garantia dos direitos trabalhistas, a criação de programas de capacitação profissional e combate à discriminação contra a mão-de-obra feminina. Quanto às políticas de geração de emprego e renda (ou combate à pobreza) numa perspectiva de gênero, fomentam projetos produtivos organizados por mulheres, capacitação e garantia de acesso ao crédito, numa constante busca de erradicação da divisão sexual do trabalho. É dentro dessa perspectiva que se situa este estudo, ou seja, analisar uma proposta de fomentar e potencializar oportunidades de trabalho e ocupação para mulheres, considerando não só a implementação de políticas públicas voltadas para estes sujeitos, mas também o acompanhamento e a avaliação do andamento das mesmas, como uma forma de ajustar, corrigir ou pressionar o Estado para a transparência e conquista dos direitos sociais. Esta é uma necessidade imperiosa para assegurar o êxito das ações.

Na perspectiva de contemplar condições igualitárias das mulheres nas políticas públicas, assim se coloca Natividade (2009):

Sobre uma participação equânime das mulheres no espaço do labor e econômico, existem entraves e desafios na elaboração e execução das políticas públicas, sob a perspectiva de gênero como: salários inferiores aos dos homens, mesmo ocupando a mesma posição profissional; os cuidados com espaço privado e alterações que vêm ocorrendo na estrutura familiar; o desemprego, participação elevada no mercado informal e em ocupações precárias e/ou sem remuneração, revelando a má qualidade das condições do trabalho feminino e alterações no padrão da divisão sexual do trabalho; mudanças sociodemográficas; a diversidade étnico-racial, entre outras (NATIVIDADE, 2009, p. 234).

Assim, é de suma importância a implementação de políticas voltadas para as mulheres no mercado de trabalho, como forma de diminuição das desigualdades existentes entre estas e os homens. Por este viés, o empreendedorismo passa a ser também uma alternativa viável para impulsionar a inserção das mulheres no trabalho e fazê-las protagonistas também na promoção do desenvolvimento econômico.

\section{0 discurso oficial sobre o Programa Nacional Trabalho e Empreendedorismo da Mulher - PNTEM}

Dentre as políticas públicas para mulheres, se insere o Programa Nacional Trabalho e Empreendedorismo da Mulher - PNTEM, que teve origem no Projeto Mulher Empreendedora, iniciado em 2005 no Rio de Janeiro, sendo institucionalizado a partir de um Acordo de Cooperação Técnica entre a Secretaria Especial de Políticas para as Mulheres - SPM da Presidência da Repú- 
blica, o SEBRAE (Serviço de Apoio às Micro e Pequenas Empresas) e a BPW Brasil (Business Professional Women - Federação das Associações de Mulheres de Negócios e Profissionais). Enquanto Projeto, realizava ações de apoio ao empreendedorismo feminino, premiava iniciativas empreendedoras e ofertava cursos de incentivo e desenvolvimento do espírito empreendedor. A partir de 2007, o Projeto Mulher Empreendedora recebeu status de Programa pela SPM e um novo formato, passando a ser chamado de Programa Rio: Trabalho e Empreendedorismo da Mulher - PTEM. Esse novo desenho estruturava o Programa em dois eixos: fomento ao empreendedorismo; trabalho e ocupação. Considerando o bom andamento da experiência vivenciada no Rio de Janeiro, em 2008, este Programa foi replicado e institucionalizado em âmbito nacional, expandindo-se para as outras regiões do país, nas unidades da federação selecionadas, a saber, Santa Catarina, Distrito Federal, Pernambuco e Pará.

O PNTEM baseava-se na Política Nacional para as Mulheres, que tem entre seus pressupostos e princípios a Equidade de Gênero, a Autonomia das Mulheres e a Universalidade das Políticas. Fundamentava-se também no II Plano Nacional de Políticas para as Mulheres (PNPM), no seu primeiro capítulo 'Autonomia Econômica e Igualdade no Mundo do Trabalho com Inclusão Social', que trata da ampliação do acesso das mulheres ao mercado de trabalho e promoção da autonomia econômica e financeira por meio de apoio ao empreendedorismo, associativismo, acesso ao crédito e ao microcrédito, distribuição e comercialização dos produtos do trabalho.

Segundo definições dos documentos oficiais, este Programa tinha como objetivo geral:

Alterar de modo significativo a inter-relação presente nos processos de desenvolvimento local e as questões de gênero, identificando os fatores de vulnerabilidade que incidem sobre a vida das mulheres em geral, em particular das mulheres pobres e extremamente pobres, no que diz respeito à ambiência produtiva, à autonomia econômica e financeira das mulheres e às posições ocupadas por elas em atividades empreendedoras e no mercado de trabalho (SECRETARIA ESPECIAL DE POLITICAS PARA AS MULHERES, 2009, p. 5).

Como público prioritário, atendia tanto mulheres pobres que queriam criar ou desenvolver negócios já existentes quanto aquelas extremamente pobres, participantes ou não dos programas de inclusão social. Além disso, na tentativa de integrar esses dois públicos ao processo, o PNTEM contemplava também gestoras e gestores públicos estaduais e municipais, que possibilitavam a transversalidade da perspectiva de gênero nas políticas públicas voltadas para os direitos das mulheres. O PNTEM era executado pelo IBAM ${ }^{3}$ (Instituto Brasileiro de Administração Municipal), pelas instituições parceiras,

3 O IBAM é uma associação civil sem fins lucrativos, criada em 1952, com sede no Rio de Janeiro. Tem como missão promover o desenvolvimento institucional do Município, fomentando o desenvolvimento local e capacitando-o para formulação de políticas, baseado na ética, transparência e independência partidária. 
EMPREENDEDORISMO E POLITIICAS PÚBLICAS: PERCEPÇÕES DAS BENEFICIÁRIAS SOBRE O PROGRAMA TRABALHO E EMPREENDEDORISMO DA MULHER EM PERNAMBUCO

$\mathrm{SEBRAE}^{4}$ e BPW ${ }^{5}$, e contava ainda com o apoio/parceria dos governos estaduais e das prefeituras. A execução se dava através de Acordo de Cooperação Técnica entre poder público e instituições parceiras.

Estava pautado em dois eixos que estruturavam suas ações:

- Fomento ao Empreendedorismo: atuação do SEBRAE direcionada à promoção de instrumentos para as mulheres criarem e gerirem de modo adequado seus próprios negócios e à oferta de um ambiente favorável aos empreendimentos sob sua iniciativa;

- Trabalho e Ocupação: atuação da BPW junto às mulheres em vulnerabilidade de risco social por renda, visando a transmissão de conhecimentos sobre direitos para a efetiva conquista da cidadania e ingresso no mundo do trabalho.

Nesse compartilhamento de responsabilidades, os papeis de cada instituição eram claramente definidos: o IBAM respondia pela coordenação e avaliação geral do Programa, bem como pela consolidação dos documentos de orientação, sustentabilidade e replicação. Convém ressaltar que, apesar da SPM ser a responsável pela política, o IBAM tinha autonomia enquanto coordenação geral. Já o SEBRAE colaborava no levantamento dos estudos das possibilidades de mercados, coordenava e executava as atividades do eixo 1 (fomento ao empreendedorismo), e ainda participava da avaliação do processo. Para a BPW recaía a coordenação e execução das atividades do eixo 2 (trabalho e ocupação), e também participação na avaliação do processo.

No período em que o Programa foi ofertado em cada Estado - geralmente de dois anos - foram executadas as seguintes atividades nas áreas geográficas definidas antecipadamente (que poderiam ser municípios, polos ou regiões, a depender do acordo firmado com o governo estadual):

- Reuniões de sensibilização para gestores públicos e representantes de entidades que trabalhavam com a temática gênero;

- Seminários sobre Trabalho e Empreendedorismo para os dois públicos prioritários mencionados anteriormente, ou seja, mulheres pobres e aquelas extremamente pobres;

- Cursos oferecidos pelo SEBRAE: Mulher Empreendedora; Juntas somos fortes; Determinação Empreendedora; Aprender a Empreender;

- Cursos oferecidos pela BPW: Políticas Públicas e Empreendedorismo da Mulher; Educação Financeira; Alfabetização Digital;

- Oficinas de Direcionamento Estratégico (de monitoramento, acompanhamento e fortalecimento dos grupos);

- Oficinas sobre Microcrédito Produtivo;

- Fóruns e Oficinas de Trabalho para Gestores Públicos.

De forma geral, o processo de implementação dessa política pública iniciava-se com a realização de reuniões entre os governos federal e estaduais, 4 O SEBRAE é uma entidade privada sem fins lucrativos, criada em 1972, que trabalha com a capacitação e desenvolvimento dos pequenos negócios do Brasil, estimulando o empreendedorismo e a sustentabilidade de tais negócios.

5 A BPW é uma organização não-governamental sem fins lucrativos, apartidária e não assistencial, fundada em 1930, em Genebra, Suíça. Tem como missão unir mulheres que utilizem suas competências para desenvolver e ampliar sua representatividade na sociedade e no mercado de trabalho. 
com a participação do IBAM e das organizações executoras, para daí delimitar os territórios a serem atendidos e seus indicadores, os papéis e responsabilidades que caberiam a cada um dos parceiros, as metas, os recursos e as formas de gestão. As atividades propriamente ditas começavam com uma reunião de sensibilização e esclarecimentos sobre o Programa para gestores, técnicos públicos, representantes de organizações integrantes da rede de atendimento na área de assistência social e trabalho das regiões e municípios selecionados. A discussão nesse momento referia-se à implementação do PTEM naquela localidade, considerando os aspectos políticos, administrativos e sociais. Também eram feitos acordos referentes ao apoio das organizações na mobilização de mulheres e do poder público, em especial no deslocamento das participantes de suas residências até o local dos cursos e oficinas que seriam oferecidos no âmbito do Programa.

Passados os quinze ou vinte dias da reunião de sensibilização, acontecia o Seminário sobre Trabalho e Empreendedorismo com as mulheres indicadas pelas organizações de desenvolvimento local presentes na reunião de sensibilização. Neste momento eram apresentados os objetivos, as atividades oferecidas e os critérios de acesso ao Programa para as mulheres. Ainda ocorria uma palestra dialogada sobre a "Mulher no Século XXI", que tinha o objetivo de mobilização das mesmas para participação no PNTEM.

É importante ressaltar que neste Seminário as mulheres que foram mobilizadas pelas Secretarias e organizações preenchiam uma ficha cadastral em que, a partir do perfil informado, eram selecionadas para participação nos cursos oferecidos pelo SEBRAE e pela BPW. As informações solicitadas nesse instrumento de seleção versavam sobre dados pessoais como: endereço, idade, cor/raça, estado civil, condição do domicílio, número de filhos, movimentos e organizações que participava, escolaridade, área e tipo de ocupação profissional, rendimentos, cursos que já havia realizado, disponibilidade para os cursos, entre outras.

Decorridos vinte dias do seminário, iniciavam-se os cursos de fomento ao empreendedorismo para as mulheres. Este processo levava cerca de dois meses e dele poderiam sair novos negócios ou até mesmo planos de melhoria na gestão dos já existentes. Os órgãos responsáveis pela execução dos cursos e oficinas com as mulheres eram o SEBRAE e a BPW. Recomendava-se que as mesmas mulheres selecionadas participassem dos quatro cursos do SEBRAE e que o outro público escolhido realizasse os três cursos oferecidos pela BPW. Concomitantemente aos cursos, eram realizadas atividades de formação sobre políticas públicas e temas concernentes a gênero, raça e direitos humanos com os gestores estaduais e municipais ou regionais. Tais atividades tinham a finalidade de sensibilizar os gestores para que os governos municipais, estaduais e distritais pudessem incorporar a perspectiva de gênero nas suas políticas, através da criação de programas específicos que, quando necessário, contribuíssem para o crescimento da autonomia econômica das mulheres. 
EMPREENDEDORISMO E POLÍTICAS PÚBLICAS: PERCEPÇÕES DAS BENEFICIÁRIAS SOBRE O PROGRAMA TRABALHO E EMPREENDEDORISMO DA MULHER EM PERNAMBUCO

Quanto ao estado de Pernambuco, o Programa foi executado entre maio de 2010 e abril de 2012, atuando na Região Metropolitana do Recife, contando com a parceria da Secretaria Especial da Mulher de Pernambuco. O Programa trabalhou considerando seis polos:

- Camaragibe e São Lourenço da Mata;

- Igarassu, Abreu e Lima, Itamaracá, Itapissuma e Araçoiaba;

- Paulista e Olinda;

- Jaboatão dos Guararapes e Moreno;

- Cabo de Santo Agostinho e Ipojuca;

- Recife.

\section{Metodologia}

Este estudo é derivado de uma pesquisa realizada para tese de doutorado, sendo de cunho qualitativo, buscando-se informações sobre experiências, representações, opiniões e significados. Assim, como primeira forma de coleta de dados realizamos uma pesquisa bibliográfica e exploratória sobre o assunto, seguida de pesquisa documental, a fim de obter informações gerais sobre o Programa. A pesquisa documental se deu a partir de dados do Programa situados no site oficial do mesmo e nas publicações do PTEM através de livros. Neste momento foi possível ter contato com a concepção do Programa, as realidades estaduais onde ele foi implementado, a divisão dos papeis e condições de atuação dos parceiros institucionais locais, entre outros. $O$ passo seguinte foi a análise do conteúdo explicitado no material didático utilizado nos sete cursos promovidos pelas duas instituições executoras, quatro apostilas do SEBRAE de mesmo título dos cursos - Mulher Empreendedora, Juntas somos fortes, Determinação Empreendedora, Aprender a Empreender - e três da BPW - Gênero e Empreendedorismo, Educação financeira, Alfabetização Digital.

Por fim, buscamos o posicionamento e a percepção das beneficiárias acerca das contribuiç̧ões para elas do Programa em termos profissionais, pessoais e sociais por meio de entrevistas individuais, procurando analisar o conteúdo das falas e das respectivas trajetórias. Foram entrevistadas 17 (dezessete) mulheres, selecionadas por acessibilidade, através do cadastro fornecido pelos órgãos executores. Logo, com consentimento e autorização das beneficiárias, a realização das entrevistas foi possível com três mulheres de Araçoiaba, duas de Igarassu, cinco do Cabo de Santo Agostinho, duas de Abreu e Lima, três de Olinda e duas de Jaboatão dos Guararapes. Buscamos, inclusive, a abordagem em bairros distintos no mesmo município para considerar as particularidades geográficas. 


\section{Olhares e percepções das beneficiárias sobre o Programa Trabalho e Empreendedorismo da Mulher em Pernambuco}

Quando se pensa em mensurar os benefícios ou resultados de uma política, a primeira perspectiva é a verificação dos objetivos pretendidos e se foram alcançados. Assim, no caso estudado, em algumas situações os resultados esperados não necessariamente se concretizaram, mas outras formas de benefícios foram percebidas pelos agentes envolvidos. Deste modo, algumas das participantes entrevistadas relataram benefícios do Programa principalmente no que concerne aos aspectos subjetivos e do ponto de vista existencial relativos à elevação da autoestima, à valorização pessoal e do autocuidado. Todavia, essas melhorias mencionadas não se reverteram de forma efetiva num protagonismo ou real participação dessas mulheres no que concerne à questão do desenvolvimento econômico. Isto traduzido na persistente referência à dificuldade de criar ou gerir um negócio, aos problemas encontrados para a formação de associações e cooperativas, e ainda aos aspectos relacionados à questão de gênero (as mesmas continuam a se responsabilizar - sem a ajuda dos maridos - pelo trabalho e cuidado com a casa, o que dificulta a conciliação do trabalho na esfera pública com a esfera privada).

Dessa forma, embora as percepções de benefícios sejam distintas do que foi proposto como objetivo, o Programa teve seu significado para as participantes no que se refere a mudanças nos olhares e opiniões. As respostas foram diversas e se concentraram, sobretudo, nos negócios, nas condições de trabaIho, nas questões pessoais e nas relativas à casa. Sendo assim, diante do que foi colocado, fizemos uma distinção entre aspectos de melhoria de natureza objetiva e os de natureza subjetiva. Embora os aspectos objetivos estivessem mais explícitos nas finalidades e nos resultados esperados do Programa estudado, os subjetivos foram amplamente difundidos nos conteúdos dos cursos que, exaustivamente, trabalharam a dimensão da elevação da autoestima das mulheres, condição fundamental para que depois elas pudessem ter êxito ao protagonizar atividades produtivas. Assim, ao se referirem aos aspectos subjetivos de melhoria pessoal, a maioria reafirmou a questão da elevação da autoestima e as amizades que construíram a partir dos cursos. Além disso, foram citados: o desenvolvimento pessoal, a empatia, a melhor comunicação, o respeito pelo outro, o trabalho em grupo, e a persistência de seu sonho (especificamente a vontade de montar seu próprio negócio). Isso nos levou a destacar dois casos que foram bem significativos, porque trouxeram uma visão que atravessava a objetividade da política; no que se refere à questão da autoestima como um dos seus maiores benefícios, bem como a melhoria de condições materiais: uma delas motivou-se para emagrecer, perdendo $23 \mathrm{~kg}$, como também conseguiu ter condições para comprar seu carro; a outra destacou a importância de ter aprendido a ter contato com computador, mesmo não sabendo ler e escrever. 
EMPREENDEDORISMO E POLÍTICAS PÚBLICAS: PERCEPÇÕES DAS BENEFICIÁRIAS SOBRE O PROGRAMA TRABALHO E EMPREENDEDORISMO DA MULHER EM PERNAMBUCO

Abordadas sobre como se sentiam ou se viam após a participação no Programa, foi bastante expressiva a manifestação de que se sentiam bem, felizes e realizadas. Em suas evocações as imagens traziam a expressão destes sentimentos: "uma nova mulher", "uma rainha", "uma pessoa melhor", "vitoriosa", "forte", "guerreira", "preparada para enfrentar qualquer coisa". Entretanto, vimos que estas manifestações não foram compartilhadas por todas as entrevistadas, pois algumas demonstraram falta de realização pessoal e frustração após o Programa, já que não conseguiram desenvolver nenhuma atividade nem estavam trabalhando. Tais registros evidenciaram que a percepção de benefício a partir das atividades perpassava os próprios objetivos do Programa. Mesmo sem conseguirem montar um negócio ou garantirem sua independência financeira em relação ao marido, muitas se mostraram realizadas em relação à motivação, aprendizagem e a (re) descoberta de suas qualidades e capacidades.

Ainda relativo aos aspectos subjetivos mencionados, foram relatados desejos despertados pelo Programa, principalmente no vislumbre de oportunidades, como o de montar ou melhorar o negócio. No entanto, foi recorrente a dificuldade para realizar esse desejo, tanto financeira como a necessidade de um acompanhamento que, segundo elas, não aconteceu. Logo, o despertar para o empreender ocorreu, inclusive, porque era conteúdo exaustivo dos cursos, mas a falta de recursos financeiros e a falta de acompanhamento foram bastante destacados pelas participantes estudadas. Isto também fica evidente na constatação de autores como Carneiro (2003), sobre a necessidade de políticas específicas para o acesso dos mais necessitados a três meios que são fundamentais para a geração de renda: o crédito, a capacitação dos trabalhadores e a intermediação de empregos. Assim, as beneficiárias reconheceram que o Programa trouxe o despertar para o empreendedorismo e aspectos necessários para isso, mas tal desejo esbarrou nos recursos financeiros para sua concretização. Quanto aos aspectos objetivos, algumas mencionaram que aprenderam a economizar no dia-a-dia ou na administração da casa. Isto pode estar relacionado, especificamente, ao curso da BPW sobre Educação financeira.

Sobre os benefícios no negócio e melhorias nas condições de trabalho foram vários aspectos mencionados, assim distribuídos:

* Aspectos concernentes à oportunidade de aprender mais;

* Os relacionados diretamente a montar ou gerir negócios: como começar um negócio, como ter uma renda melhor, como realizar vendas, como colocar preço, a fazer distinção entre apurado e lucro, aprendizagem sobre fluxo de caixa, aprendizagem sobre investir primeiro no negócio para depois ter retorno, sobre custo fixo e custo variável, a percepção de que não existe lucro de imediato, como administrar, sobre marketing, e sobre capital de giro.

* Além desses, mencionaram ainda a questão da formalização, embora bem poucas entrevistadas afirmaram ter conseguido concretizar isto;

* Sobre aquisição de máquinas ou equipamentos: quanto a isto algumas 
confirmaram que desenvolveram seus negócios a partir da compra de equipamentos, ou passaram a utilizar a internet como ferramenta para facilitar suas vendas;

* Melhorias na renda e nas vendas, entre outros.

Tais benefícios registrados pelas informantes nos aspectos objetivos têm estreita relação com a visão contemporânea do empreendedorismo, apontada por Santiago (2009), que inclui a noção de competência: o saber (conhecimento), o saber fazer (habilidade) e o querer fazer (atividade).

Soma-se a esta a perspectiva de Oliveira e Guimarães (2006), que mencionam estudos que consideram outros fatores fundamentais para o êxito do empreendedorismo, como: o suporte das agências governamentais, através de mecanismos de financiamento; facilidades para o acesso ao crédito; a infraestrutura industrial do país e as políticas públicas de incentivo aos novos negócios.

Dentre os principais objetivos do Programa estava incluído o desenvolvimento da capacidade empreendedora e a possibilidade de criação de um ambiente favorável a novos negócios. Assim, analisando as atividades realizadas pelas informantes antes e depois da participação no Programa, pudemos perceber três aspectos importantes a serem analisados:

1. O desenvolvimento de negócios/ atividades nas dependências da própria residência (revelando a necessidade de estratégia de conciliação de funções com as responsabilidades familiares);

2. Que as atividades que tinham realizado (ou que ainda realizavam) remetiam a ocupações socialmente construídas como sendo tipicamente femininas (artesanato, culinária, beleza);

3. E ainda que os discursos sobre as percepções das entrevistadas quanto ao desenvolvimento de negócios e às melhorias alcançadas eram bastantes distintos (para umas a percepção de benefício poderia se referir em desenvolver um pequeno negócio em casa, para outras o ter podido formalizar empreendimentos já existentes ou ainda apreender a separação entre montante lucrado e aquele para investimento).

Na perspectiva de Swedberg (2000) e Thorton (1999) é preciso analisar o empreendedorismo pelo viés social e cultural, e não considerando apenas os fatores econômicos e psicológicos. Isto porque o empreendedorismo é um processo muito dinâmico, e está sujeito a mudanças constantes a partir dos contextos sociais, econômicos e culturais.

No que se refere aos planos e desejos despertados pelo Programa, a maior parte das beneficiárias informou que almejava montar seu próprio negócio ou progredir no que já possuía, e dentre as metas a serem empreendidas estavam a criação de loja de artesanato, de buffet (organização de festas), produção e venda de confecções, restaurante, comércio relacionado à alimentação (preparação de lanches, doces e salgados por encomenda), atividades que, como enfatizamos, fazem parte daquelas consideradas próprias do universo feminino. Das dezessete entrevistadas, apenas duas mencionaram a vontade de desenvolver atividades em grupo, a partir da formação de cooperativas, número muito in- 
EMPREENDEDORISMO E POLÍTICAS PÚBLICAS: PERCEPÇÕES DAS BENEFICIÁRIAS SOBRE O PROGRAMA TRABALHO E EMPREENDEDORISMO DA MULHER EM PERNAMBUCO

significante, uma vez que um dos objetivos do PTEM era justamente estimular as mulheres à organização de associações e cooperativas, enfatizando inclusive com a oferta de um curso específico sobre isto, intitulado 'Juntas somos fortes'. Perseguindo os nossos objetivos, um dos aspectos que nos interessava verificar foi qual a contribuição que o Programa propiciou, através das ações implementadas, para redimensionar a questão de gênero tanto nas atividades empreendedoras, bem como nos espaços sociais e familiares.

Os autores que vêm tratando as questões de gênero procuram reforçar que este conceito é relacional, ou seja, qualquer mudança ou protagonismo feminino só se dá no âmbito das relações entre homens e mulheres, e mostram como o gênero se coloca enquanto categoria historicamente vinculada à diferença, à desigualdade e à exclusão. Quanto a isso, Bourdieu (1999, p. 136) menciona que

O esforço no sentido de libertar as mulheres da dominação, isto é, das estruturas objetivas e incorporadas que se lhes impõem, não se pode se dar sem um esforço paralelo no sentido de liberar os homens dessas mesmas estruturas que fazem com que eles contribuam para impô-la.

Tratando-se especificamente do empreendedorismo feminino, apesar de ser um fenômeno crescente, tem apresentado mais características de necessidade do que de oportunidade em relação aos homens, ou seja, as mulheres têm buscado tal estratégia de sobrevivência por não encontrarem outra forma de gerar renda (em oposição aos homens, que empreendem mais por oportunidade e apresentam características de vocação empreendedora). Dessa forma, um dos questionamentos que mais geraram confusão para resposta das beneficiárias foi sobre a opinião acerca deste ser um Programa voltado somente para mulheres e que os homens não podiam participar. Algumas entrevistadas chegaram a opinar que o Programa deveria se estender à participação dos homens, pois estes também têm direito de aprender e assim seria um meio de transformação da situação familiar no sentido de que o homem teria outra visão da posição da mulher e esta poderia transpor os espaços exclusivos de mando e ação masculinas. Contudo, muitas veem a presença unicamente feminina como uma conquista, mostrando esse momento como sendo a chance e a vez das mulheres aparecerem, e que estas necessitam mais que os homens. Logo, como gênero é relacional, ou seja, se refere à relação entre homem e mulher, de fato pode-se pensar que pela exclusão da figura masculina, o Programa reforça a questão do gênero tanto excluindo o homem da participação das atividades, como também das oficinas voltadas para gestores. Assim, como integrar a perspectiva de gênero nas políticas públicas visando reduzir as desigualdades (conforme objetivo da oficina para gestores) se não conta com a presença de gestores homens, que muitas vezes são os que mais estão à frente das ações governamentais? 
No âmbito do trabalho, o Programa em nada modificou a natureza das atividades oferecidas. De fato, o desenvolvimento de um novo negócio se deu, prioritariamente, em trabalhos considerados tipicamente femininos, como os de cabeleireira, diaristas, entre outras. Acrescenta-se a isso a concepção adotada nos cursos do SEBRAE de que homens e mulheres possuem dentro de si princípios masculinos e femininos: afirmavam as ideias de que as mulheres são sensíveis, intuitivas, receptivas, cuidadosas e possuem ternura, interioridade e profundidade; enquanto que os homens são racionais, objetivos, assertivos, materialistas e possuem expressividade. Estas colocações terminaram por reforçar o estereótipo de que o comportamento dos indivíduos responde ao instinto e é natural, quando, ao contrário, o comportamento, papeis e funções dos indivíduos são construídos culturalmente.

Esta perspectiva apareceu com clareza no relato de uma Gestora, que mencionava que algumas beneficiárias comentaram "que o curso do SEBRAE sugeria muito ocupações nesse sentido, femininas". Assim, vislumbrar as atividades realizadas após o Programa e também os "desejos" e vontades despertados a partir dos cursos remetem à reprodução de uma divisão sexual do trabalho. Nesse sentido, ao invés de fomentar ou abrir espaço para o desenvolvimento de outras atividades, o Programa termina por fortalecer a permanência de atividades que sempre foram simbolicamente pertencentes ao universo feminino. Observando o material utilizado nos cursos, também foram recorrentes os exemplos e histórias que afirmavam isto, como por exemplo, a costura, confecção, cabeleireiro, produção de sabonetes, produção e venda de alimentos.

Um dos mais importantes espaços para se identificar a dimensão das relações de gênero é o espaço familiar. No caso de nossas entrevistadas suas experiências domésticas só reafirmaram esta constatação. Antes do Programa, a maior parte das entrevistadas, falando sobre a rotina familiar, informou que cuidava sozinha dos afazeres domésticos. Em alguns casos as filhas ajudavam, mas somente as filhas, nunca os filhos, já em outro contava com o trabalho de uma diarista, e uma delas recebia o auxílio da sogra. O participar no Programa não provocou mudanças nesta rotina, como bem colocaram muitas das entrevistadas. Aquelas que relataram mudanças, referiram-se à abertura para o diálogo (aprender a ouvir e a se comunicar melhor), à libertação em deixar mais os filhos, a dar mais atenção e cuidar mais do marido, passar a trabalhar no negócio do marido, e ficar mais independente.

Apesar de o Programa trabalhar a perspectiva da autonomia da mulher e das mudanças nas relações familiares, no que se refere aos cuidados com a casa as mudanças não foram percebidas. Grande parte das mulheres continua cuidando da casa sozinha e precisando conciliar trabalho e afazeres domésticos. Tal dado só fez revelar a dificuldade de uma mulher empreender, uma vez que o homem tem a possibilidade de se dedicar somente aos negócios, enquanto que a mulher empreendedora não. Esta tem que se dividir entre seu negócio e as tarefas domésticas, fazendo com que os empreendimentos sejam desenvolvidos nas dependências da casa, reforçando assim a costumeira dupla jornada de trabalho. 
EMPREENDEDORISMO E POLÍTICAS PÚBLICAS: PERCEPÇÕES DAS BENEFICIÁRIAS SOBRE O PROGRAMA TRABALHO E EMPREENDEDORISMO DA MULHER EM PERNAMBUCO

Perguntadas sobre as mudanças que observaram em si mesmas após o Programa, poucas mencionaram melhoras no relacionamento familiar. $\mathrm{O}$ formato machista se reafirma nestes espaços não sendo sequer posto em questão. As respostas deixaram de mencionar esse debate passando a se concentrar em aspectos outros como os relacionados à valorização e cuidados pessoais. Encontramos algumas das nossas informantes que mencionaram ter depressão ou se sentirem oprimidas antes de participar das atividades do PTEM, mas, com o Programa, se viram mais capazes, mais pacientes, mais fortes, passaram a lutar sem desistir, e, numa particularidade, uma delas registrou que deixou até de ser racista e homofóbica. Outro ponto destacado foi a importância do Programa para quem não teve oportunidade de estudo, apresentava dificuldade com leitura, ou não tinha desenvoltura para se expressar com clareza. Também houve relato de uma beneficiária que já sofreu violência doméstica e aprendeu a se impor diante do companheiro.

Apesar desses avanços de postura na relação homem/mulher, ainda tivemos uma das entrevistadas que, apesar de ter sua própria renda, deixou que o marido continuasse com o seu tradicional papel de provedor da casa, ela não participando em nada das despesas domésticas. Exemplos como este só fazem reforçar a atuação de persistência do machismo já tão presente nos espaços familiares do Nordeste.

Além deste caso, foram observadas durante os cursos outras atitudes semelhantes. Uma delas se deu no polo 1, onde o marido só permitia que sua esposa, uma senhora idosa, participasse dos cursos se ele fosse levá-la e buscá-la, e assim aconteceu, durante as quatro semanas: todos os dias ele chegava com ela e ficava aguardando por toda a tarde o término das atividades, inclusive em alguns momentos observava o que estava acontecendo. E a outra situação, de maior gravidade, ocorreu durante um dos cursos, que entre as atividades tinha uma voltada para o dia da beleza, para isso contava com a presença de maquiadores e cabeleireiros na preparação das participantes para uma sessão de fotos objetivando a elevação da autoestima. Apesar de muitas entrevistadas mencionarem isso e se recordarem positivamente, uma das participantes sofreu agressões físicas do esposo quando chegou em casa com outro visual no cabelo e maquiada, chegando até a questionar o tipo de curso ofertado.

Dessa forma, foi notório que o Programa, apesar de objetivar alterar as relações presentes nas questões de gênero e incluir essa perspectiva nas prioridades de gestão, ele esbarrou em entraves culturais e sociais comumente difíceis de serem transpostos. Como por exemplo, os aspectos que já mencionamos da não inclusão de gestores homens nas oficinas de gênero para sensibilização, a reprodução do discurso dos afazeres domésticos destinados apenas às mulheres, a elaboração de atividades já habitualmente relativas às mulheres (corte e costura, faxina, alimentação), visíveis atitudes machistas, levando a inviabilizar a realização das atividades fora dos espaços de casa para que assim as mulheres pudessem conciliar a nova atividade com os afazeres domésticos. Soma-se $a$ isso a persistência por parte dos homens em considerarem a renda da mulher como complementação ou simples ajuda do orçamento familiar. 


\section{Considerações finais}

Tendo por objetivo verificar os benefícios e as experiências de empreendedorismo fomentadas a partir da implementação do Programa Trabalho e Empreendedorismo da Mulher no estado de Pernambuco percebemos então que, em linhas gerais, o Programa - para algumas das participantes - teve seus méritos e trouxe benefícios, ainda que não tenham sido os postos como objetivos nos documentos oficiais. O significado por elas atribuído aos benefícios foi mais perceptível no que se refere às mudanças produzidas nos olhares e opiniões sobre si mesmas e não necessariamente ao seu protagonismo e efetiva participação que tenha produzido desdobramentos sobre o desenvolvimento econômico local. Aliás, considerando as dificuldades persistentes apontadas por estas mulheres em criarem ou gerirem um negócio (seja individualmente ou em grupo) ou os obstáculos em garantir a sua independência financeira em relação aos maridos, ficamos a questionar a eficácia dos cursos e dos conteúdos repassados visando instrumentalizá-las para empreender e assim assegurar sua autonomia.

Os aspectos subjetivos, comportamentais e existenciais foram exaustivamente destacados pelas entrevistadas como benefícios advindos da participação nos cursos e oficinas, pois garantiram um novo olhar sobre si mesmas graças à elevação da autoestima, da valorização pessoal e maior cuidado de si mesma, aumentando sua motivação para empreender, para a aprendizagem, a (re) descoberta de suas qualidades e capacidades. Por esse viés, houve de fato um despertar para abrir seu próprio negócio, mas tal desejo esbarrou na ausência de recursos financeiros e na expectativa de um acompanhamento que não ocorreu.

Uma das questões-chave do Programa se referia a de proporcionar um redimensionamento da questão de gênero nas atividades empreendedoras e também nos espaços familiares e sociais, até porque, no que se refere ao empreendedorismo feminino, embora seja um fenômeno que cresce a cada ano no Brasil, tem características diferenciadas em relação ao empreendedorismo masculino. As mulheres recorriam, em sua maioria, a esta forma de gerar renda por não encontrar outras formas (empreendedorismo por necessidade), e a esse dado somavam-se outros aspectos: os negócios eram empreendidos no âmbito doméstico para facilitar a conciliação com os afazeres de casa (dupla jornada de trabalho); as atividades escolhidas em geral remetiam a ocupações simbolicamente destinadas a mulheres (como as relacionadas à cozinha, artesanato, beleza); as mulheres continuavam a ser responsabilizadas sozinhas pelos trabalhos domésticos (o que já se colocava como um entrave para desenvolver as atividades, pois o homem podia se dedicar inteiramente aos negócios, enquanto que as mulheres precisavam se dividir entre o trabalho público e o do espaço doméstico, privado).

Isso foi observado também no caso das beneficiárias do PTEM entrevistadas para este trabalho. Inclusive vimos que, em alguns pontos, a política reforçava tais estereótipos e comportamentos social e culturalmente esperados quando trazia determinados exemplos e histórias nos materiais utilizados 
EMPREENDEDORISMO E POLÍTICAS PÚBLICAS: PERCEPÇÕES DAS BENEFICIÁRIAS SOBRE O PROGRAMA TRABALHO E EMPREENDEDORISMO DA MULHER EM PERNAMBUCO

nos cursos, quando sugeria ocupações tipicamente femininas, quando afirmava que homens e mulheres possuíam características diferentes - as mulheres eram sensíveis, receptivas, cuidadosas e os homens mais racionais, objetivos e materialistas - todas essas imagens eram repassadas em cursos com pequena carga horária e que as beneficiárias poderiam estar aproveitando melhor se aprofundando nos assuntos referentes à gestão dos negócios, por exemplo. Assim, o Programa se deparou localmente com entraves sociais e culturais no que diz respeito a estas questões de gênero tradicionalmente difíceis de serem quebradas, como atitudes visivelmente machistas de alguns maridos, a não participação de gestores homens nas oficinas de gênero para sensibilização, a reprodução do discurso dos afazeres domésticos como próprios somente às mulheres, dentre outros.

Quanto à questão do empreendedorismo, percebemos dificuldade por parte das beneficiárias ao expressarem suas concepções sobre esse fenômeno, bem como em relacionar empreendedorismo e trabalho. Todavia, quando assim o fizeram, os discursos remetiam aos conteúdos repassados durante as atividades do Programa, que traziam uma visão positiva do empreendedorismo, como algo gerador de renda, que combatia a pobreza e trazia desenvolvimento econômico. Por essa ótica, o empreendedor era aquele que transformava oportunidades em negócios de sucesso, tomava decisões, trazia inovações, assumia riscos. Em momento algum se percebeu alusão a outras facetas do empreendedorismo: que este poderia contribuir também para reprodução da desigualdade e da exclusão, ou a que nem todos os sujeitos tinham vocação para empreender; ou que, não necessariamente, o empreendedorismo seria uma alternativa ao desemprego. Assim, um dos questionamentos evidentes para nós foi se a política que fomenta o empreendedorismo não seria uma forma de transferir a responsabilidade do Estado para o sujeito ou, o contrário, pelo viés da política pública, uma forma de diminuir as desigualdades.

Mais um dos impasses percebidos em Pernambuco foi a dificuldade das participantes desenvolverem seus negócios de forma coletiva, quer através da formação de associações ou de cooperativas. Houve poucas tentativas de formação de grupos, mas estas não lograram êxito, seja por falta de apoio e acompanhamento, seja por problemas nos relacionamentos entre as participantes, seja pelo número reduzido de beneficiárias em determinadas localidades. Tal fato se desenhou como mais uma das fragilidades da política ou da forma como as orientações eram repassadas, pois nos cursos e oficinas se estimulava fortemente a formação de empreendimentos em grupo, mas, na prática, as ideias não vingavam. Dessa forma, como em toda política pública, observamos que existem desafios e obstáculos no processo de implementação. Por ser um processo contínuo que envolve diversos atores, expectativas e contextos, as políticas públicas estão sujeitas a distorções e necessidades de ajustes durante todo o processo para que a integração e a interação entre os sujeitos tragam a efetividade esperada. 


\section{REFERÊNCIAS}

BOURDIEU, Pierre. A dominação masculina. Rio de Janeiro: Bertrand Brasil, 1999.

BRUSCHINI, Cristina. Fazendo as perguntas certas: como tornar visível a contribuição econômica das mulheres para a sociedade? In: ABRAMO, L.; ABREU, A. R. Gênero e Trabalho na Sociologia Latino-Americana. São Paulo/ Rio de Janeiro: ALAST, 1998.

CANTELLI, P. O. O trabalho feminino no divã: dominação e discriminação. São Paulo: LTR, 2007.

CARNEIRO, F. G. Perfil da pobreza e aspectos funcionais dos mercados de trabalho no Brasil. In: Pobreza e mercados no Brasil. Brasília: CEPAL/DFID, 2003.

CORTES, S. V.; LIMA, L. L. A contribuição da Sociologia para a análise de políticas públicas. Lua nova, São Paulo, n. 87, p. 33-62, 2012

COSTA, Cândida. Trabalho e Subjetividade. In: COSTA, Cândida. Nas malhas da instabilidade: os trabalhadores públicos em um cenário de mudanças. São Luís: EDUFMA, 2008. p. 35-109.

DYE, Thomas. Understanding Public Policy. Englewood Cliffs: Prentice-Hall, 1984.

FRIEDMANN, John. Empowerment: uma política de desenvolvimento alternativo. Celta: Oeiras, 1996.

HEIDMANN, F. G. Do sonho do progresso às políticas de desenvolvimento. In: HEIDMANN, F. G.; SALM, J. F. (Org.). Políticas públicas e desenvolvimento: bases epistemológicas e modelos de análise. Brasília: UnB, 2009.

LASWELL, H. D. Politics: who gets what, when, how. Cleveland: Meridian Books, 1958.

MACHADO, Hairam. Espaços interacionais e discursividades sobre gênero e desenvolvimento no Programa Trabalho e Empreendedorismo da Mulher e no Projeto Com licença, eu vou à luta no Distrito Federal. Brasília, 2012. Dissertação de Mestrado (Programa de Pós-graduação em Estudos Comparados sobre as Américas) - Universidade de Brasília.

NATIVIDADE, Daise Rosas. Empreendedorismo feminino no Brasil: políticas públicas sob análise. Revista de Administração Pública, Rio de Janeiro, n. 43, p. 231-256, jan./fev. 2009.

OLIVEIRA, D. C.; GUIMARÃES, L. O. Perfil empreendedor e ações de apoio ao empreendedorismo: o NAE/SEBRAE em questão. Economia e Gestão, Belo Horizonte, v. 6, n. 13, 2006.

SANTIAGO, E. G. Vertentes teóricas sobre empreendedorismo em Shumpeter, Weber e McClelland: novas referências para a Sociologia do Trabalho. Revista de Ciências Sociais, São Paulo, v. 40, n. 2, p. 87-103, 2009.

SECRETARIA ESPECIAL DE POLÍTICAS PARA AS MULHERES - SPM. Programa Pernambuco: Trabalho e Empreendedorismo da Mulher. 2009.

SILVA, C. L.; BASSI, N. S. S. Políticas públicas e desenvolvimento local. In: SILVA, Christian Luiz (Org.). Políticas Públicas e Desenvolvimento Local: instrumentos e proposições de análise para o Brasil. Petrópolis: Vozes, 2012.

SILVA, P. L. B.; COSTA, N. R. A avaliação de programas públicos: reflexões sobre a experiência brasileira. Brasília: IPEA, 2002.

SILVA E SILVA, Maria Ozanira da. Avaliação de Políticas e Programas Sociais enquanto momento do processo das Políticas Públicas. In: SILVA E SILVA, Maria Ozanira (Org.). Avaliação de Políticas e Programas Sociais: teoria e prática. São Paulo: Veras, 2001.

SILVA E SILVA, Maria Ozanira da. Avaliação de Políticas e Programas Sociais: uma reflexão sobre o conteúdo teórico e metodológico da pesquisa avaliativa. In: SILVA E SILVA, Maria Ozanira (Coord.). Pesquisa avaliativa: Aspectos teórico-metodológicos. São Paulo: Veras, 2008.

SWEDBERG, R. The social view of entrepreneurship. In: SWEDBERG, R. The social science view. Oxford: Oxford University Press, 2000.

THORNTON, P. The sociology of entrepreneurship, Annual Review of Sociology, n. 25, p.19-46, 1999. 